\title{
Development of garment with elastic straps and pressure applicator in mechanotherapy to correct children's genu valgum
}

\begin{abstract}
Objective: Genu valgum (GV), also known as valgus knee, or knock-knee, is a common orthopaedic condition in growing children. Physiological genu valgum have intermalleolar distance of up to $8 \mathrm{~cm}$, the greatest distance being observed between 3 and 4 years, disappearing gradually after the age of 7-8 years. If the longitudinal axis of the knee joint is not aligned by then, physiotherapeutic intervention is called for.
\end{abstract}

Aim: The aim of our study was to determine if garment with elastic straps and pressure applicator could be used in mechanotherapy to correct children's excessive GV.

Methods: The study has lasted last 6 years and there has been three study periods. In all study-periods, practical part lasted six months. Inclusion criterias were: subjects were not involved in physical therapy and did not wear orthoses during the study. Once in every month myometric values (tone, biomechanical and viscoelastic properties of $\mathrm{m}$. sartorius, tensor fasciae latae, semitendinosus, tibialis anterior, gastrocnemius caput mediale, m. peroneus longus) were determined with MyotonPro (Myoton AS, Estonia); anthropometric (height, body mass, intermalleolar distance), and goniometric (tibiofemoral angle) parameters were measured according to the standard technique. During the last three months children didn't wear garment and final measurement was done to evaluate long term effect of garment. Individual analysis was carried out to evaluate the results.

Results: After wearing the garments with pressure and elastic components the changes in the lower limb joint alignment and biomechanical parameters promoted the correction of GV position. Three months after the wearing period the changes occurred the worsening of GV position, which indicates that the muscles could not maintain the condition achieved by wearing the garment.

Conclusion: The relationship between applied mechano therapeutic stimulus and changes in the lower limb joint alignment and changes of the biomechanical parameters are individual. Study continues with upgrading a device where a new solution is found using digital technology to measure tensile strength at a desired period.

Keywords: children, genu valgum, valgus knee, knock-knee, myometria, mechanotherapy, gespa, tibiofemoral angle, intermalleolar distance
Volume 3 Issue 3 - 2018

\author{
Anna-Liisa Tamm,' Reet Linkberg,' Ivi Vaher,' \\ Mari-Liis Luukas,' Maaria Pielberg,' Eva \\ Nigulas,' Laura Laanesaar,' Karoliina Pertel,' \\ Kärt Satsi,' Arved Vain ${ }^{2}$ \\ 'Tartu Health Care College, Physiotherapy and environmental \\ health department, Estonia \\ ${ }^{2}$ University of Tartu, Training Centre of Medical Physics and \\ Biomedical Engineering, Estonia
}

Correspondence: Anna-Liisa Tamm, Physiotherapy and environmental health department, Tartu Health Care College, Nooruse 5, 504I I Tartu, Estonia, Tel +3725285 I8I,

Email annaliisatamm@nooruse.ee

Received: April 25, 20I8 | Published: May 14, 2018

\section{Introduction}

Genu valgum $(\mathrm{GV})$, also known as valgus knee, or knock-knee, is a common orthopedic condition in growing children, the prevalence is approximately $7 \%{ }^{1}$ In 2 to 6 year-old children, valgus knee is quite normal within certain limits of tibiofemoral angle (TFA), ${ }^{2}$ which is defined as the angle between the anatomical axis of femur with the anatomical axis of tibia), ${ }^{3}$ and it is expressed indirectly as intercondylar distance and intermalleolar distance (IMD). ${ }^{4}$ Physiological GV in childhood have IMD of up to $8 \mathrm{~cm}$, the greatest distance being observed between 3 and 4 years, ${ }^{5}$ disappearing gradually after the age of 7-8 years. ${ }^{6}$ If the longitudinal axis of the knee joint is not aligned by then, and the IMD is more than $5 \mathrm{~cm},{ }^{7}$ physiotherapeutic intervention is called for. The degree of GV has a significant effect on the development of growing pains ${ }^{8}$ and orthrosis because the imposed loads are no longer equally distributed between the outer and the inner halves of the knee. ${ }^{9}$ This is the best time-period for deflexion correction. ${ }^{10}$ Optimal dosage of mechanical therapies can stimulate the body's condition and properties in the desired direction, while reducing the duration of the impaction process. ${ }^{11}$ The musculoskeletal system adapts to physical influences or lack thereof, which in turn affects the biomechanical function of the musculoskeletal system. Asymmetrically effective forces cause asymmetric growth and may cause both deformation of the joints to deepen. The components of the musculoskeletal system are particularly susceptible to these forces during the rapid growth period. This is also the best time to correct any abnormalities. ${ }^{10}$

There are several non-invasive methods of correcting GV (methods based on the principle of kinesio-tape; Thera Togs Ultra; different type of garments), but until now, there is no equipment or method to evaluate mechanotherapeutic intervention while the process is ongoing so that timely decisions could be made on the effectiveness of the intervention. The aim of our study was to determine if garment with elastic straps and pressure applicator ${ }^{11,12}$ could be used in mechanotherapy to correct children's excessive GV. 


\section{Methods}

The study is carried out as an applied research project in collaboration with Tartu Health Care College and University of Tartu. The study was approved by Tallinn Medical Research Ethics Committee with identifier number 2790 (2012).

The study has been lasted last six years and there has been three study periods. In all periods (2012-2013;2014-2015;2016-2017) practical part lasted six months, once in every month anthropometric (height, body mass, IMD), goniometric parameter (TFA in lying down and standing position), and myometric values (tone, biomechanical and viscoelastic properties of $\mathrm{m}$. sartorius, $\mathrm{m}$. tensor fasciae latae, $\mathrm{m}$. semitendinosus, $\mathrm{m}$. tibialis anterior, $\mathrm{m}$. gastrocnemius caput mediale) were measured. Participants wore special garment every day at least 6-8 hours for three months. During the last three months children didn't wear garment and final measurement was done to evaluate long term effect of garment.

All anthropometrical and goniometrical measurements were done according to the standard technique: IMD, ${ }^{13}$ TFA. ${ }^{3}$ Body height was measured using a Harpender metal anthropometer to the nearest 0.1 $\mathrm{cm}$, body mass was measured with minimal clothing to the nearest $0.1 \mathrm{~kg}$ with a medical electronic scale (A\&D Instruments, Ltd, Abingdon, UK), and body mass index (BMI) was calculated (BMI $=\mathrm{kg} /$ $\mathrm{m}^{2}$ ). To determine the tone, biomechanical and viscoelastic properties of skeletal muscles myometric method in multiscan mode was used. MyotonPRO (Myoton AS, Estonia) allow to assess the condition of the surface skeletal muscles safely, non-invasively, cost-effectively and in real time. ${ }^{14}$

The study included children who had GV deformity (IMD $5 \mathrm{~cm}$ or more). The condition for inclusion was that the subjects were not involved in physical therapy and did not carry orthoses during the study. In the first study period, the GV control group was included, which did not wear garments.

\section{Description of the garment}

\section{I study period (20 I 2-20 I3)}

Subjects $(\mathrm{n}=12)$ wore specially sewn garment (Figure 1) with elastic straps based on the individual dimensions of the child. A $5 \mathrm{~cm}$ wide strip of elastic material was sewn to the garment at the entire length of the lower extremity, similar to the kinesiotaping methodology. The tensile strength of the installed strap was set on the dynamometer. Similarly to the kinesiotaping methodology the joints and the muscular physiological processes of the lower extremity were supported and stabilized by elastic stripe, providing a necessary amount of mobility for the lower extremity while preventing excessive stretching of the muscle. The garments were comfortable for the child and easy to put on with the help of a parent. Children wore the garments for three months and daylong. Although during and after the study some limitations of the garments were observed: there was no possibility to regulate and measure tensile strength of the installed strap, the used material lost its shape and supportive function.

\section{II study period (20|4-20 I5)}

All subjects $(\mathrm{n}=2)$ wore specially sewn garment with elastic straps and pressure applicator (GESPA; Figure 2) for three months and they were told to wear them at least eight hours a day. Garments were equipped with sensor (Force Sensing Resistor, FSR) sensing pressure applied to medial localized part of knee joint. ${ }^{11,12}$ The optimal tensile strength was computed between 1-2N. If the tensile strength was not in correct range the signal light occured. It was possible to adjust the tensile strength with a flexible tape running from under the sole. Limitations of the garment-the light signal was often unnoticed, so there was a need for an alternative signal.

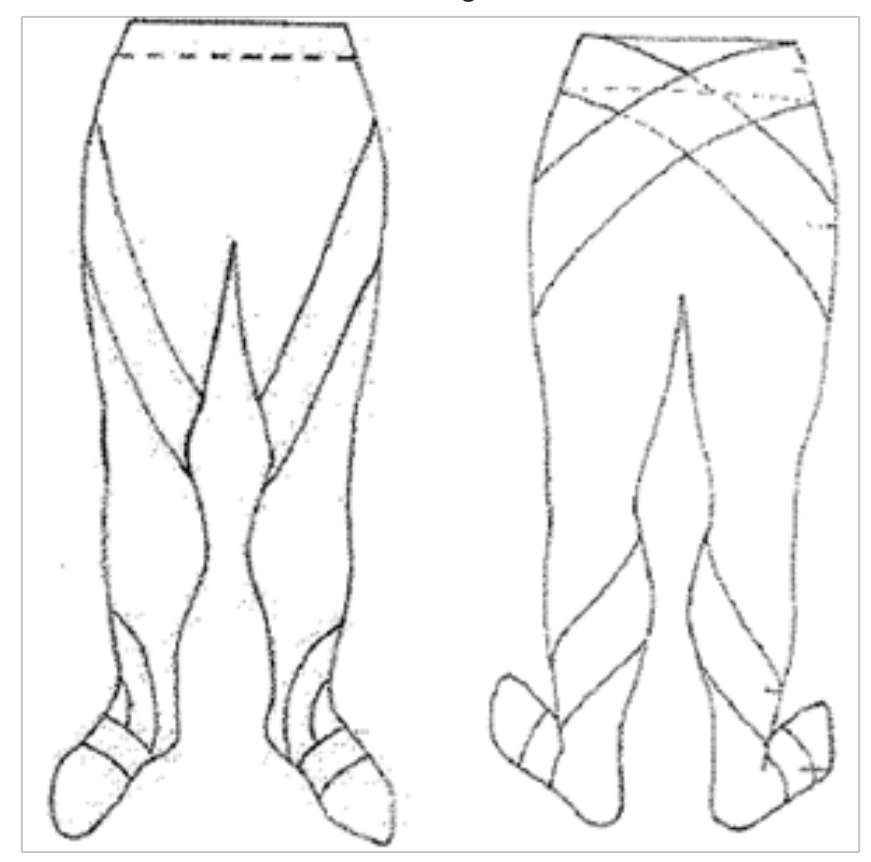

Figure I Specially sewn garments with elastic straps (I study period).
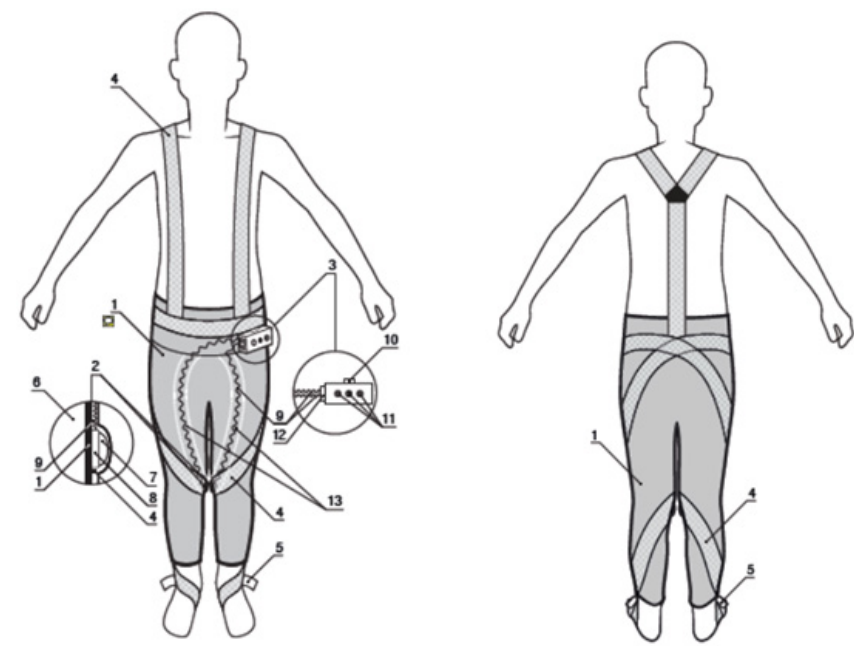

Figure 2 Garments with elastic straps and pressure applicator (GESPA). I,garments; 2,pressure applying mechanism; 3, control unit; 4, elastic straps; 5 , adjuster for adjustment of stress in the elastic straps; 6 , body; 7 , spherical segment; 8,pressure sensor; 9, wires; I0, on-off switch; I I, light (study period II) and sound indicators (study period III); 12 , sockets; 13 , channels in the garment and pockets for sensor.

\section{III study period (20I6-20I7)}

In the third study period, all subjects $(\mathrm{n}=6)$ wore GESPA, where an acoustic signal was added (signal light removed) which signalled about the tensile strength (too low or high). 
The statistical package for the social science (SPSS 20) was used for statistical analysis the influence of wearing garment was detected with paired t-test. For estimating the skeletal muscle tone (oscillation frequency- $\mathrm{Hz}$ ) and biomechanical properties: logarithmic decrement and dynamic stiffness $(\mathrm{N} / \mathrm{m})$, individual analysis was carried out MultiScan pattern of 20 measurements was used, and the mean was considered (MyotonPro User manual. The $p$ value of $<0.05$ was considered significant.

\section{Results}

Mean $( \pm \mathrm{SD})$ of subjects characteristics in the beginning of each study period are presented in Table $1 . \mathrm{GV}$ is not associated with the sex, ${ }^{15}$ so the results are presented altogether.

In first study period according to National Center for Health Statistics, all subjects of our study were overweight (BMI $>19)$ or obese $(\mathrm{BMI}=27.8)$. All subjects had normal BMI in study period II and III. GV position was indicated according to the IMD values (Table 1). In first study period there were no changes in IMD and TFAs/TFAl values during the wearing period in experimental group. In II and III study period TFA and IMD values decreased which shows the improvement of the alignment of the lower limb.

Table I Mean $( \pm S D)$ of subjects characteristics in the beginning of each study period

\begin{tabular}{llllllll}
\hline Period & SG & n & Age $(\mathbf{y})$ & Height $(\mathbf{c m})$ & Weight $(\mathbf{k g})$ & BMI $\left(\mathbf{k g} / \mathbf{m}^{2}\right)$ & IMD $(\mathbf{c m})$ \\
\hline I & EG & 12 & $5.83 \pm 0.9$ & $120.2 \pm 9.9$ & $27.8 \pm 8.8$ & $19.2 \pm 3.1$ & $6.2 \pm 3.7$ \\
& CG & 4 & $6.8 \pm 0.5$ & $125.5 \pm 3.7$ & $31.0 \pm 2.8$ & $19.7 \pm 3.5$ & $6.6 \pm 2.0$ \\
II & EG & 2 & $6.5 \pm 0.7$ & $128.0 \pm 9.9$ & $25.5 \pm 0.7$ & $15.8 \pm 2.9$ & $7.8 \pm 1.2$ \\
III & EG & 6 & $7.2 \pm 1.9$ & $124.9 \pm 10.2$ & $28.1 \pm 8.2$ & $17.5 \pm 3.3$ & $7.2 \pm 2.1$
\end{tabular}

SG, study group; EG, experimental group; CG, control group; IMD, intermalleolar distance

The biomechanical parameters of the muscles are very individual, so the results of these parameters are presented in Tabel 2 as an example of one subject. There were significant differences in parameters between left and right side of the body, but the changes were greater on that side in which a higher abnormality was detected at the first measuring. There were positive changes (shows the correction of $\mathrm{GV}$ ) in biomechanical parameters (frequency $=\mathrm{F}$; decrement $=\mathrm{D}$; stiffness $=S$ ) in all subjects ( $\uparrow$-increasing; $\downarrow-$ decreasing):

i. m. semitendinosus $-\mathrm{F}=\uparrow ; \mathrm{D}=\downarrow ; \mathrm{S}=\uparrow$;

ii. m. tensor fasciae latae $-\mathrm{F}=\downarrow ; \mathrm{D}=\uparrow ; \mathrm{S}=\downarrow$;

iii. $\quad$ m. sartorius $-\mathrm{F}=\uparrow ; \mathrm{D}=\downarrow ; \mathrm{S}=\uparrow$;

iv. $\quad \mathrm{m}$. tibialis anterior $-\mathrm{F}=\uparrow ; \mathrm{D}=\downarrow ; \mathrm{S}=\uparrow$;

v. $\quad$ m. gastrocnemius caput mediale $-\mathrm{F}=\uparrow ; \mathrm{D}=\downarrow ; \mathrm{S}=\uparrow$.

Three months after the wearing period the changes occurred promoted the worsening of GV position in all study periods (I,II,III).

Table 2 The biomechanical parameters (decrement, stiffness) and frequency of the muscles

\begin{tabular}{|c|c|c|c|c|c|c|c|c|c|c|c|c|}
\hline \multirow{3}{*}{ Muscle } & \multicolumn{6}{|c|}{ Pre-wearing period } & \multicolumn{6}{|c|}{ Post-wearing period } \\
\hline & \multicolumn{2}{|c|}{ Frequency } & \multicolumn{2}{|c|}{ Decrement } & \multicolumn{2}{|c|}{ Stiffness } & \multicolumn{2}{|c|}{ Frequency } & \multicolumn{2}{|c|}{ Decrement } & \multicolumn{2}{|c|}{ Stiffness } \\
\hline & II & $\mathrm{rl}$ & II & $\mathrm{rl}$ & II & $\mathrm{rl}$ & II & $\mathrm{rl}$ & II & $\mathrm{rl}$ & II & $\mathrm{rl}$ \\
\hline semitendinosus & 14.3 & $14.5^{*}$ & 1.19 & $\mathrm{I} .09 *$ & 235 & $219 *$ & $15.2 * *$ & $14.9 * ; * *$ & $1.03 * *$ & $1.09 *$ & $262^{* *}$ & $244 * ; * *$ \\
\hline tensor fasciae latae & 13.6 & $13.3^{*}$ & 0.75 & $0.70 *$ & 237 & $211 *$ & $11.9 * *$ & $12.8 * ; * *$ & $0.85^{* *}$ & $0.79 * ; * *$ & $159 * *$ & $183 * ; * *$ \\
\hline sartorius & 12 & 12.4 & 1.08 & $1.17 *$ & 164 & $|7| *$ & $12.3 * *$ & $12.9 * ; * *$ & $1.02 * *$ & $0.96 * ; * *$ & $168 * *$ & $186 * ; * *$ \\
\hline tibialis anterior & 18.2 & $17.5^{*}$ & 1.13 & $1.17 *$ & 355 & $340 *$ & $22.0 * *$ & 19.6*;** & $0.94 * *$ & $0.89 * ; * *$ & $444 * *$ & $399 * ; * *$ \\
\hline $\begin{array}{l}\text { gastrocnemius caput } \\
\text { mediale }\end{array}$ & 12.4 & $13.4^{*}$ & 1.17 & $1.13 *$ & 169 & $183^{*}$ & $14 .\left.\right|^{* *}$ & $13.5^{*}$ & $0.96 * *$ & $1.10 *$ & $208 * *$ & $197 * ; * *$ \\
\hline
\end{tabular}

LI,left leg; rl, right leg; ${ }^{*}$,difference with left leg; ${ }^{* *}$,change compared with pre-wearing period

\section{Discussion}

The alignment of the lower limb (evaluated by IMD) should be balanced usually after age of 8 years. ${ }^{6}$ In Tallinn (Estonia), secondgrade schoolchildren $(8-9 \mathrm{y} ; \mathrm{n}=4427)$ have IMD approximately $0.3 \mathrm{~cm}$, but $1.78 \%$ of them have still IMD $\geq 5 \mathrm{~cm}$ (unpublished data, 2016). It shows the lasting problem, which may cause functional disturbances as altered gait pattern, postural instability, and difficulties in standing, walking, running, and stair climbing. ${ }^{16}$ Adults with uncorrected GV are prone to different knee problems (painful knee, joint instability, chondromalacia, osteoarthritis) and injuries. ${ }^{17}$ There is a need for non-invasive, painless, and effective method for young children, which helps to prevent and treat excessive GV. Researchers from Tartu Health Care College and University of Tartu are creating one possible method-GESPA, it is really easy to use, comfortable to wear for children, and the price for parents is in the future also hopefully reasonable.

$\mathrm{GV}$ is associated with vitamin-D deficiency, ${ }^{18}$ knee injuries, syndromic and metabolic problems, ${ }^{19}$ and obesity. ${ }^{4,20,21}$ In our first study period all participants were overweight (II and III study period normal BMI) but free from other mentioned diagnosis.

According to the results ' primary data analysis it may say that after II and III study period wearing the garment with tensile strength stripe 
and elasticity components for three months the changes in the lower extremity joint alignment and biomechanical parameters promoted the correction of GV position. Wearing garment prevented the GV alignment in the lower extremity, as there was a tendency to decrease the IMD, more for those subjects with the actual intensity of the mechanotherapy stimulus remained close to the selected range $(1-2 \mathrm{~N})$ and whose who wore garment for a longer time during the day. No changes in IMD and TFA values in the first study period was probably because the garments lost their shape and the supporting function to knee joint disappeared.

TFA reach a maximum at seven years ${ }^{22}$ and the differences might be associated also with race and ethnicity. ${ }^{4,6,16,23,24}$ The average TFA value at the age of 7-8 years is $4-8^{\circ}, 6,16$ and if it is $\geq 8^{\circ}$, it should be considered abnormal and further evaluation should be necessary. ${ }^{16}$ In our study in first study period children had essentially higher TFA values in all six measurement points, which might be explained by obesity, height, and increased tone and stiffness of $\mathrm{m}$. tensor fascia latae.

Garment with tensile strength and elastic components affects the frequency (tone) and biomechanical parameters (decrement, stiffness) of the muscles that holds the optimal alignment of knee joint. According to our results the formation of GV is promoted by slight elasticity (decrement) of $\mathrm{m}$. gastrocnemius caput laterale and low tone and stiffness of $\mathrm{m}$. tibialis anterior and $\mathrm{m}$. peroneus longus. The higher tone and stiffness of $\mathrm{m}$. sartorius holds the stability of the knee joint, allowing tibia to move slightly lateral direction to maintain the optimal alignment of lower extremity. Higher decrement of the $\mathrm{m}$. tensor fascia latae and higher stiffness of $\mathrm{m}$. semimembranosus stabilize the knee joint.

In our II and III study period, three months after the wearing period the changes occurred promoted the worsening GV position, which indicates that the muscles could not maintain the condition achieved by wearing the garment. However, the changes occurred during the wearing period were greater than those having occurred after the wearing period, which refers to the ability of the muscles to partially maintain the condition achieved by wearing the garment. Although the changes occurred were mainly individual and differed among subjects.

The one-way development of the results was probably affected by some limitations. Firstly the garments FSR device for measuring the tensile strength was often switched off because the audio signal that signalled about the wrong tensile strength bothered the child's everyday life. Therefore, the device could not store the tensile strength exerted by the garments during the entire period of wearing garment, and it was not known whether the generated mechano transduction stimulus was within the recommended range or not. Secondly, participants wore the garments less than 8 hours during the day, which probably lessened the garments` effectiveness. Thirdly, we cannot make any final conclusions because of quite small number of participants in our study.

\section{Conclusion}

In conclusion it may say that relationship between applied mechanotherapeutic stimulus and changes in the lower extremity joint alignment and biomechanical parameters are individual. Study continues with upgrading a device where a new solution is found using digital technology to measure tensile strength at a desired period.

\section{Acknowledgements}

We would like to thank all the participants and their parents for their time and patience. We are also grateful for our co-workers from University of Tartu, The Health Clinic, Ermiine LLC; and European Union Regional Development Fund for the help of publishing the article.

\section{Conflict of intrest}

Tartu Health Care College, University of Tartu and The Health Clinic, European Union Regional Development Fund.

\section{References}

1. Ciaccia MCC, Pinto CN, Golfieri FC, et al. Prevalence of genu valgum in public elementary schools in the city of Santos (SP), Brazil. Rev Paul Pediatr. 2017;35(4):443-447.

2. Navarro RD, Joelhos V. In: Bruschini S (editor) Ortopedia pediatrica. $2^{\text {nd }}$ ed. Atheneu 8, São Paulo; 1998.

3. Mathew SE, Madhuri V. Clinical tibiofemoral angle in south Indian children. Bone and Joint Research. 2013; 2(8):155-161.

4. Olufeni OO, Akinpelu AO, Odole AC. Development of tibiofemoral angle in a kohort of Nigerian children during the first 3 years of life. $J$ Child Orthop. 2013;7(2):167-173.

5. Heath $\mathrm{CH}$, Staheli LT. Normal limits of knee angle in white children genu valgum and genu varum. J Pediatr Orthop. 1993;13(2):259-262.

6. Arazi M, Öğün TC, Memik R. Normal Development of the Tibiofemoral Angle in Children: A Clinical Study of 590 Normal Subjects From 3 to 17 Years of Age. Journal of Pediatric Orthopaedics. 2001;21(2):264-267.

7. Guzman H, Yaszay B, Scott VP, et al. Early experience with medival femoral tension band plating in idiopathic genu valgum. Journal of Children's orthopaedics. 2011;5(1):11-17.

8. Kaspiris A, Chronopoulos E, Vasiliadis E. Perinatal risk factors and genu valgum conducive to the onset of growing pains in early childhood. Children. 2016;3(34).

9. Kapandji IA. Fisiologia articular: Tronco e coluna vertebral. Membro inferior, 2001.

10. Lowes LP, Sveda M, Gajdosik CG, et al. Musculosceletal Development and Adaptation. In: Campbell SK, Palisano RJ, Orlin MN, editors. Physical Threapy for Children. 4th ed. Elsevier Saunders: St Louis; 2012.

11. Vain A, Linkberg R, Vaher I, et al. Mechanotherapeutic Device and Measurement Method. 2015.

12. Vain A, Linkberg R, Vaher I, et al. Mechanotherapeutic Device and Measurement Method. United States US. 2017..

13. Bafor A, Omota B, Ogbemudia AO. Correlation between clinical tibiofemoral angle and body mass index in normal Nigerian children. International Orthopaedics. 2012;36(60:1247-11253.

14. Alev K, Vain A, Aru M, et al. Glucocorticoid-Induced Changes in Rat Skeletal Muscle Biomechanical and Viscoelastic Properties: Aspects of Aging. Journal of Manipulative and Physiological Therapeutics. 2018;41(1):19-24.

15. Kaspiris A, Zaphiroulou C, Vasiliadis E. Range of variation of genu valgum and association with anthropometric characteristics and physical activity: comparsion between children aged 3-9 years. Journal of Pediatric Ortopaedics. 2013;22(4):296-305. 
16. Stevens PM, Maguire M, Dales MD, et al. Physeal stapling for idiopathic genu valgum. Journal of Pediatric Ortopaedics. 1999;19(5):645-649.

17. Lim K, Hui J, Lim A, et al. Genu varum and valgum. In: Sivanathan S, Sherry E, Warnke P, Miller MD, editors. Mercer's textbook of orthopaedics. London: Hodder Arnold; 2012;667-670.

18. Djennane M, Lebbah S, Roux C, et al. Vitamin D status of schoolchildren in Northern Algeria, seasonal variations and determinants of vitamin D deficiency. Osteoporos Int. 2014;25(5):1493-1502.

19. Dhar SA, Butt MF, Mir MR, et al. A reciprocating ledge technique in closing wedge osteotomy for genu valgum in adolescents. J Orthop Surg. 2009; 17(3):313-316.

20. Rahmani NF, Daneshmandi H, Irandoust KH. Prevalence of Genu Valgum in Obese and Underweight Girls. World Journal of Sport Sciences. 2008;1(1):27-31.
21. Taylor ED, Theim KR, Mirch MC, et al. Orthopedic Complications of Overweight in Children and Adolescents. Pediatr. 2006; 117(6):21672274.

22. Baruah RK, Kumar S, Harikrishnan SVJ. Developmental pattern of tibiofemoral angle in healthy north-east Indian children. Child Orthop. 2017;11(50:339-347.

23. Saini UC, Bali K, Sheth B, et al. Normal development of the knee angle in healthy Indian children: a clinical study of 215 children. $J$ Child Orthop. 2010;4(6):579-586.

24. Yoo JH, Choi IH, Cho TJ, et al. Development of tibiofemoral angle in Korean children. J Korean Med Sci. 2008;23(4):714-717. 